\title{
Application of gum Arabic in the production of spray-dried chokeberry polyphenols, microparticles characterisation and in vitro digestion method
}

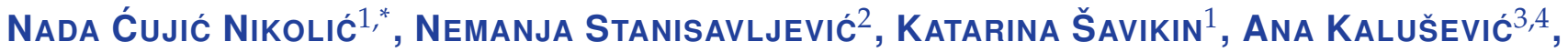 \\ Viktor Nedović ${ }^{3}$, Dubravka Bigović ${ }^{1}$, ANd TeOdora Janković ${ }^{1}$ \\ ${ }^{1}$ Institute for Medicinal Plant Research "Dr. Josif Pančić”, Tadeuša Košćuška 1, 11000 Belgrade, Serbia \\ ${ }^{2}$ University of Belgrade, Institute of Molecular Genetics and Genetic Engineering, Vojvode Stepe 454a, 11000 Belgrade, Serbia \\ ${ }^{3}$ University of Belgrade, Faculty of Agriculture, Nemanjina 6, 11080 Zemun, Serbia \\ ${ }^{4}$ Institute of Meat Hygiene and Technology, Kaćanskog 13, 11000 Belgrade, Serbia \\ *Corresponding author: ncujic@mocbilja.rs
}

Received: November 09, 2018

Accepted: November 22, 2018

Published on-line: December 20, 2018

Published: December 25, 2018

\begin{abstract}
Due to its high content of phenolics, black chokeberry has been proposed as a health-promoting material, especially use of chokeberry extract as a food or pharmaceuticals. Chokeberry extract was spray-dried using gum Arabic as a carrier. The optimal conditions for the efficient microencapsulation of chokeberry extract using spray-drying technique have been investigated. The aim of our study was to obtain microparticles with the best potential to improve functionality and stability of extracted chokeberry polyphenols, and to investigate the possibility of microbeads to protect active compounds during simulated digestion process. Morphological characteristics of microbeads were analyzed using FTIR and SEM techniques. Zeta potential, particle size and moisture content were determined. Released total phenolics and total anthocyanins content as well as concentration of individual anthocyanins were quantified before and after digestion process. Microparticles exhibited high encapsulation efficiency up to $87 \%$, and high content of released polyphenols was achieved. After in vitro simulated digestion phenolic compounds decreased by 11-24\%, exhibited higher protective effect of gum Arabic. Our results showed that chokeberry microparticles obtained by spray drying method could be useful supplements or functional food.
\end{abstract}

Key words: chokeberry, microencapsulation, spray drying, gum Arabic, phenolics, digestion

http://dx.doi.org/10.1364/leksir1838009C

\section{INTRODUCTION}

In recent years, the utilization of natural products, especially natural antioxidants have substantially increased following the trends of chronic diseases reduction. Among many natural antioxidants, plant polyphenols have attracted special attention due to their high biological activity. The small dark violet berry, known as chokeberry, as one of the richest plant sources of phenolics, especially anthocyanins, have growing interest for their utilization, mainly due to their antioxidant potential and due to numerous health-promoting activities (gastroprotective, hepatoprotective, antiproliferative or antiinflammatory activities) (Kulling and Rawel, 2008; Rugina et al., 2012). Confirmed beneficial effects, such as prevention of cancer, coronary heart disease, diabetes, and other degenerative disorders, are also well known (Castañeda-Ovando et al., 2009; Kokotkiewicz et al., 2010; Sainova et al., 2012). Chokeberry (Aronia melanocarpa [Michx] Elliot, Rosaceae) originating from North America, which was introduced to Eastern Europe, Scandinavia and Russia in early 20th century (Kokotkiewicz et al., 2010; Kulling and Rawel, 2008). Chokeberries are widely recognized as valuable source of bioactive compounds such as anthocyanins, flavonols, procyanidins and phenolic acids (neochlorogenic and chlorogenic acids) (Bräunlich et al., 2013; Kulling and Rawel, 2008; Rugina et al., 2012; Sueiro et al., 2006). This fruit species is utilized mainly as juices, teas, beverages, purees, jams, jellies, wine and other food products (González-Molina et al., 2008; Kokotkiewicz et al., 2010; Kulling and Rawel, 2008) but extracts are less present on the market trade. On the other hand, chokeberry extracts are one of the most interesting forms for food and pharmaceutical use due to the high amount of active principles they contain, but extracts do not provide long-term storage stability of polyphenols, especially anthocyanins (Ćujić et al., 2016b). Extracted polyphenols also have limited bioavailabil- 
ity (Bakowska-Barczak and Kolodziejczyk, 2011). Problem with polyphenols instability and low bioavailability can be solved by microencapsulation technology (Bakowska-Barczak and Kolodziejczyk, 2011; Belščak-Cvitanović et al., 2015; Fang and Bhandari, 2011), which has tendency to improve the stability of extracts during storage and processing, and damaging effects of gastrointestinal tract. Spray drying is simple, low cost and one of the most convenient microencapsulation tehnique for controlled production of small particles with uniform and desirable size, covering unpleasant (bitter) taste of phenolics and increasing their bioavailability (Bakowska-Barczak and Kolodziejczyk, 2011; Belščak-Cvitanović et al., 2011; Fang and Bhandari, 2011). Gum Arabic, natural biopolymer is one of the most applied carrier materials (Belščak-Cvitanović et al., 2015; de Souza et al., 2015), due to its excellent biocompatibility, possibility to protect the actives compounds, as well as its biodegradability and non-toxicity (Idham et al., 2012; Tolun et al., 2016; Tonon et al., 2009). Gum Arabic, exudates gum of Acacia tree, is a hetero-polysaccharide complex, highly ramified structure. Gum Arabic is the only gum used for food products and it is characterized by high solubility and low viscosity in aqueous solution, appropriate for the spray drying process (Tonon et al., 2009). To the best of our knowledge, there are no reports about microencapsulation of chokeberry polyphenols using gum Arabic as a carrier.

The aim of this study was to protect sensitive compounds from chokeberry extract, especially anthocyanins, using spray drying method, as well to characterise microencapsulated powder and investigate the impact of digestion process on stability of active phenolic compounds.

\section{MATERIALS AND METHODS}

\subsection{Chemicals}

Folin-Ciocalteu, sodium carbonate, gallic acid, methanol, formic acid and potassium bromide were obtained from Sigma-Aldrich (Steinheim, Germany). Ethanol was of analytical grade, acetonitrile (Merck, Germany) was of HPLC grade, and ultra-pure water was prepared using a Milli-Q purification system (Millipore, France). The anthocyanin standards cyanidin-3-galactoside, cyanidin-3-glucoside and cyanidin3-arabinoside were purchased from Extrasynthese (Cedex, France). Gum Arabic was supplied by Davisco Foods International (Le Sueur, MN, USA).

\subsection{Plant material}

Berries were collected from plantation located on the mountain Suvobor, Serbia (700 m altitude) in July 2017 at fully ripened stage, and subsequently dried in a laboratory dryer (Instrumentaria ST 01/02, Zagreb, Croatia) at $40^{\circ} \mathrm{C}$ for $48 \mathrm{~h}$. Dried berries were grounded by industry mill and obtained particles were separated using sieve 0.75 according to Yugoslavian Pharmacopeia (Ph.Yug.V, 2000).

\subsection{Extract preparation}

Dried berries were extracted with $50 \%$ ethanol on an orbital shaker (170 rpm) for 60 minutes, and solid to solvent ratio was $1: 20$. These extraction conditions were previously chosen as optimal for the extractions of chokeberry polyphenols (Ćujić et al., 2016a). After the extraction process, ethanol was evaporated under vacuum and aqueous chokeberry extract (CE) was obtained.

\subsection{Encapsulation of chokeberry extracts by spray drying method}

Spray drying method was applied for microencapsulation of $\mathrm{CE}$, using gum Arabic as carrier agent. Coating material was added in a previously prepared CE to obtain an encapsulant content of $5 \%(\mathrm{w} / \mathrm{v})$. The resulting solution was heated to $40^{\circ} \mathrm{C}$, mixed and homogenized well prior to spray drying. A spray dryer (Büchi mini B-290, Büchi Labortechnik AG, Switzerland) with a $0.7 \mathrm{~mm}$ standard diameter nozzle was used to prepare the spray-dried powders with inlet $\left(130 \pm 3^{\circ} \mathrm{C}\right)$ and outlet $\left(56 \pm 2^{\circ} \mathrm{C}\right)$ temperature, respectively. Relatively low spraying air flow rate $(536 \mathrm{~L} / \mathrm{h})$, liquid feed $(8 \mathrm{~mL} / \mathrm{min}$ rate), atomization pressure ( $6 \mathrm{psi}$ ) and low inlet temperature were chosen in order to ensure a good atomization along the liquid feed rate and to obtain a stable powder (specially to ensure anthocyanins stability) with high actual loading. Free-flowing powders were obtained and subjected to analysis (Figure 1). Powder was transferred to high-density polyethylene zip-lock plastic bags and stored in the dark at $-20^{\circ} \mathrm{C}$ for later analyses.

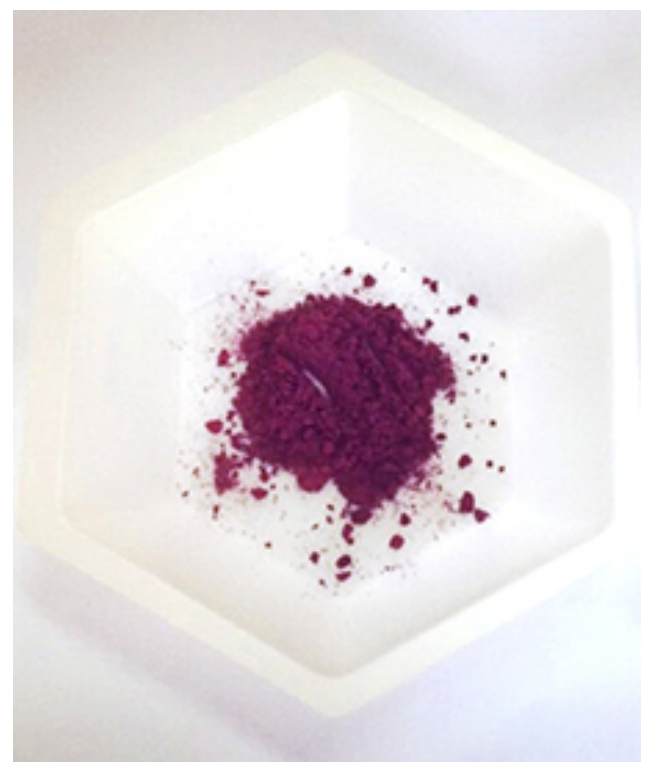

Fig. 1. Spray-dried chokeberry extract using gum Arabic as a carrier

\subsection{Characterisation of microbeads}

\subsubsection{Moisture content}

The moisture content of the powder was determined termogravimetrically, drying the beads until constant weight in Halogen Moisture Analyzer HB43-S (Mettler Toledo).

\subsubsection{Particle size}

The size of the encapsulated microbeads was determined using Mastersizer 2000 (Malvern Instruments, Worcester-shire, UK). The mean diameter over volume (also called DeBroukere mean) was used as representative diameter.

\subsubsection{Fourier-transform infrared spectroscopy (FTIR) analysis}

Transmission spectra of obtained spray dried powder was recorded using a IRAffinity ${ }^{-1}$ Fourier transform infrared spectrophotometer (Schimadzu, Japan) and $\mathrm{KBr}$ disc sampling technique. Microbeads were mixed with $\mathrm{KBr}$ powder and compressed to pastilles. Infrared spectra over the wavelength range 4000 to $600 \mathrm{~cm}^{-1}$ were recorded and the resolution was $4 \mathrm{~cm}^{-1}$.

\subsubsection{Scanning electron microscopy - SEM analysis}

The surface morphology of the obtained spray-dried sample was examined by scanning electron microscopy (TESCAN Mira3 microscope, Czech Republic). The sample was attached to stubs using a two-sided adhesive tape, then coated with a layer of gold $(50 \mathrm{~nm})$ and examined using an acceleration voltage of $4-5 \mathrm{kV}$. 


\subsubsection{Zeta potential}

The spray-dried microparticles were analysed in order to define physical stability, and zeta potential was measured using Malvern Zetasizer Nano ZS (Malvern Instruments, Worcestershire, UK). Sample was measured three times at room temperature in deionised water and the averages were taken as results.

\subsection{Release studies}

The release of polyphenolic compounds from the obtained spray-dried microbeads was performed in release mediums at room temperature. A known amount of particles (about 5 g) was suspended in $100 \mathrm{~mL}$ release medium (distilled water) for analysis of total phenolics content, and around $200 \mathrm{mg}$ of sample in 5\% formic acid as anthocyanins release medium. The samples were submitted to continuous agitation on an orbital shaker (Unimax 1010, Heidolph, Germany) operating at $170 \mathrm{rpm}$, to simulate the gut movement. An aliquot $(1 \mathrm{~mL})$ of the supernatant was taken for analysis and centrifuged, and supernatant was used for chemical analyses. The release profiles of microbeads were investigated determining the total phenolic content and total anthocyanins content.

\subsection{Total phenolic content (TPC) in microbeads}

The total phenolic content was determined by a modified Folin-Ciocalteu method (Waterman and Mole, 1994). Briefly, $200 \mu \mathrm{L}$ of extract or microbeads solution was added to $1 \mathrm{~mL}$ of 1:10 diluted Folin-Ciocalteu reagent. After $4 \mathrm{~min}, 800 \mu \mathrm{L}$ of sodium carbonate $(75 \mathrm{~g} / \mathrm{L})$ was added. After $2 \mathrm{~h}$ of incubation at room temperature, the absorbance at $765 \mathrm{~nm}$ was measured by a spectrophotometer (Hewlett Packard, 400N). Gallic acid $(0-100 \mathrm{mg} / \mathrm{L})$ was used as a standard for calibration curve. The results were expressed as milligrams of gallic acid equivalents per gram of beads.

\subsection{Total anthocyanins (TA) in microbeads}

The total anthocyanins content was investigated according to the procedure described in Ph.Eur.8.0. (2014), with slight modifications. The absorbance of the solution was measured at $528 \mathrm{~nm}$, using a $0.1 \%(\mathrm{v} / \mathrm{v})$ solution of hydrochloric acid in methanol as the compensation liquid. The content of anthocyanins, expressed as cyanidin-3-glucoside chloride, was calculated from the expression: A $\times 5000 / 718 \times \mathrm{m}(\mathrm{A}=\mathrm{ab}-$ sorbance at $528 \mathrm{~nm} ; 718=$ specific absorbance of cyanidin3-glucoside chloride at $528 \mathrm{~nm} ; \mathrm{m}=$ mass of extracts to be examined in grams). The results were presented as milligrams of cyanidin-3-glucoside equivalents per gram of beads.

\subsection{HPLC analysis of the released anthocyanins from mi- crobeads}

The concentration of individual anthocyanins in microbeads was determined using the HPLC method. Analyses were carried out on Agilent series 1200 RR HPLC instrument (Agilent, Waldbronn, Germany), with DAD detector, on a reverse phase Lichrospher RP-18 (Agilent) analytical column (250 x $4 \mathrm{~mm}$ i.d., $5 \mu \mathrm{m}$ particle size). The mobile phase consisted of solvent A ( $10 \%$ of formic acid in water) and solvent B (acetonitrile). Samples were separated by gradient elution according to the following scheme: $1 \%$ B 0-0.5 min; 1-7\% B 0.5-1 min; 7\% B 1-4 min; 7-10\% B 4-7.5 min; 10-14\% B 7.5-11.5 min; $14-25 \%$ B 11.5$15.5 \mathrm{~min} ; 25-40 \%$ B $15.5-18.5 \mathrm{~min} ; 40-75 \%$ B $18.5-22 \mathrm{~min} ; 75 \%$ B 22-25 min. Flow was adjusted to $1 \mathrm{~mL} / \mathrm{min}$, and detection wavelengths were set at 290, 350 and $520 \mathrm{~nm}$. Quantification was done using calibration curves of anthocyanin standards cyanidin-3-galactoside, cyanidin-3-glucoside and cyanidin-3arabinoside.

\subsection{Encapsulation efficiency}

The percentage of loading (encapsulation) efficiency (EE) for investigated sample was calculated as the ratio between the total polyphenols (TP), total anthocyanins (TA) or individual compounds content in the aqueous solutions of dissolved spray-dried sample and their respective content in the initial infeed solutions, according to the equation:

$$
E E(\%)=\frac{E}{E_{\text {total }}} \times 100
$$

, where $\mathrm{E}$ is the amount of total polyphenols, total anthocyanins or individual anthocyanins encapsulated in the microbeads, and Etotal is the amount of total polyphenols, total anthocyanins or individual anthocyanins and their respective content in the initial extract used for the preparation of microbeads, according to the procedures described in the upper sections.

\subsection{In vitro gastrointestinal digestion}

Encapsulated particles were subjected to digestion by a standardized static in vitro digestion method suitable for food (Minekus et al., 2014) improved according to Versantvoort et al. (2004) in order to apply physiologically based model of human digestive tract which simulates feeding conditions. Oral phase of simulated digestion starts by mixing of $1 \mathrm{~g}$ of particles or water (control) with $4 \mathrm{~g}$ of infant formula of defined composition which simulates standard meal (food matrix). Used infant formula (Juvitana, Swisslion Product d.o.o. Indjija, Serbia) contained 3\% protein, 10\% carbohydrate and $1 \%$ fat, and was prepared from turkey meat, boiled corn paste, boiled potato paste, rice flour, sodium chloride and water according to manufacture specification and free of preservatives, antioxidants and artificial aromas. Obtained $5 \mathrm{~g}$ of mixture was supplemented with $3.5 \mathrm{~mL}$ of simulated salivary fluid (SSF), $0.5 \mathrm{~mL}$ of salivary $\alpha$-amylase solution (1500 $\left.\mathrm{U} \mathrm{mL}^{-1}\right)$, $25 \mu \mathrm{L}$ of $0.3 \mathrm{M} \mathrm{CaCl}_{2}$ and $975 \mu \mathrm{L}$ of water and thoroughly mixed. Incubation of obtained mixture lasted for $2 \mathrm{~min}$ at $37^{\circ} \mathrm{C}$, without shaking. In the gastric phase, $10 \mathrm{~mL}$ of oral bolus was mixed with $7.5 \mathrm{~mL}$ of simulated gastric fluid (SGF), $1.6 \mathrm{~mL}$ of porcine pepsine solution $\left(25000 \mathrm{U} \mathrm{mL}^{-1}\right)$, prepared in SGF, $5 \mu \mathrm{L}$ of $0.3 \mathrm{M} \mathrm{CaCl}_{2}$ and $\mathrm{pH}$ was adjusted to 3.0 using $1 \mathrm{M} \mathrm{HCl}$. The mixture was supplemented to a volume of 20 $\mathrm{mL}$ by addition of distilled water and subjected to incubation at $37^{\circ} \mathrm{C}$ during $2 \mathrm{~h}$, using orbital shaker adjusted to $300 \mathrm{rpm}$. For the intestinal phase, $20 \mathrm{~mL}$ of gastric chyme was supplemented with $11 \mathrm{~mL}$ of simulated intestinal fluid (SIF), $5 \mathrm{~mL}$ of pancreatine prepared in SIF $\left(800 \mathrm{U} \mathrm{mL}^{-1}\right.$, based on trypsin activity), and mixed with $2.5 \mathrm{~mL}$ of $160 \mathrm{mM}$ bile salt solution, $40 \mu \mathrm{L}$ of $0.3 \mathrm{M} \mathrm{CaCl}_{2}$. The $\mathrm{pH}$ value of the mixture was adjusted to 7.0 with $1 \mathrm{M} \mathrm{NaOH}$ and volume was supplemented with water to reach $40 \mathrm{~mL}$. Samples were incubated for $2 \mathrm{~h}$ at $37^{\circ} \mathrm{C}$ with constant shaking on orbital shaker at $300 \mathrm{rpm}$. After completed digestion, samples were centrifuged at 10000 rpm for $10 \mathrm{~min}$ at $4^{\circ} \mathrm{C}$, supernatants were recovered and their volume was accurately measured. Supernatants were then frozen in liquid nitrogen and kept for further experiments at $-80^{\circ} \mathrm{C}$. Detailed composition of SSF, SGF and SIF electrolyte solutions is presented in Table 1.

\subsection{Data analysis}

All measurements were performed in triplicates. The data in Tables were presented as mean \pm standard deviation.

\section{RESULTS AND DISCUSSION}

\subsubsection{Moisture content}

The moisture content plays a significant role in establishing the shelf-life of powders and in this research had value of $4.87 \%$ 
Table 1. Composition of stock solutions and simulated digestion fluids

\begin{tabular}{|c|c|c|c|c|c|}
\hline \multirow{4}{*}{ Compounds } & \multirow{3}{*}{\multicolumn{2}{|c|}{ Stock conc. }} & \multirow{4}{*}{$\begin{array}{r}\text { pH } 7.0 \\
\text { Conc. in SSF } \\
{\left[\mathrm{mmol} \mathrm{L}^{-1}\right]}\end{array}$} & \multirow{4}{*}{$\begin{array}{r}\text { SGF } \\
\text { pH } 3.0 \\
\text { Conc. in SGF } \\
{\left[\mathrm{mmol} \mathrm{L}^{-1}\right]}\end{array}$} & \multirow{4}{*}{$\begin{array}{r}\text { SIF } \\
\mathrm{pH} 7.0 \\
\text { Conc. in SSF } \\
{\left[\mathrm{mmol} \mathrm{L}^{-1}\right]}\end{array}$} \\
\hline & & & & & \\
\hline & & & & & \\
\hline & {$\left[\mathrm{g} \mathrm{L}^{-1}\right]$} & {$\left[\mathrm{mol} \mathrm{L}^{-1}\right]$} & & & \\
\hline $\mathrm{KCl}$ & 37.3 & 0.5 & 15.1 & 6.9 & 6.8 \\
\hline $\mathrm{KH}_{2} \mathrm{PO}_{4}$ & 68 & 0.5 & 3.7 & 0.9 & 0.8 \\
\hline $\mathrm{NaHCO}_{3}$ & 84 & 1 & 13.6 & 25 & 85 \\
\hline $\mathrm{NaCl}$ & 117 & 2 & - & 47.2 & 38.4 \\
\hline $\mathrm{MgCl}_{2}\left(\mathrm{H}_{2} 0\right)_{6}$ & 30.5 & 0.15 & 0.15 & 0.1 & 0.33 \\
\hline$\left(\mathrm{NH}_{4}\right)_{2} \mathrm{CO}_{3}$ & 48 & 0.5 & 0.06 & 0.5 & - \\
\hline $\mathrm{NaOH}$ & - & 1 & - & - & 8.4 \\
\hline $\mathrm{HCl}$ & - & 6 & 1.1 & 15.6 & - \\
\hline $\mathrm{CaCl}_{2}\left(\mathrm{H}_{2} \mathrm{O}\right)_{2}$ & 44.1 & 0.3 & 0.75 & 0.075 & 0.3 \\
\hline
\end{tabular}

a SSF-simulated salivary fluid; SGF-simulated gastric fluid; SIF- simulated intestinal fluid.

(Table 2). Low moisture content is commonly observed in spray-dried particles produced by this technique, and largely is influenced by the humidity and temperature of the drying process (Bakowska-Barczak and Kolodziejczyk, 2011; BelščakCvitanović et al., 2015; Fang and Bhandari, 2011). Tolun et al. (2016) demonstrated that addition of gum Arabic in the other coating materials (maltodextrin) decreased the moisture content of microencapsulated particles. Higher moisture content induces to microbial growth and powders caking, which affects to the physical and chemical stability (Goyal et al., 2015). The moisture content of less than $5 \%$ is required for good and long term stability, efficient packing and storaging (BelščakCvitanović et al., 2015). This is in accordance with the previously published results for chokeberry spray-dried juice powder (Horszwald et al., 2013) and chokeberry juice encapsulated using maltodextrin (Wilkowska et al., 2017). This moisture content depended on different encapsulating agents, polyphenols type, and inlet temperature used for spray drying process. Higher drying temperature (above $140^{\circ} \mathrm{C}$ ) reduced the moisture content but may cause the instability of anthocyanins and polyphenols (Bakowska-Barczak and Kolodziejczyk, 2011). Used gum Arabic showed good properties of obtained powder moisture content, which is very important for furtherer industrial use.

\subsection{Particle size}

Preferred particle size depends on its future application. Larger particles provide sustained and prolonged release of encapsulated compounds, while smaller beads are better in the terms of organoleptic characteristics, which is important for application as a food or pharmaceutical products(Ćujić et al., 2016a). Particle size of obtained microparticles had average of $14.92 \mu \mathrm{m}$ using this carrier and extract (Table 2, Figure 2 ), which confirmed that spray drying is suitable method for small particles production with uniform size. Similar results were reported by Righetto and Netto (2005) andDib Taxi et al. (2003). Belščak-Cvitanović et al. (2015) showed that only usage of Acacia (gum Arabic) and guar gum provided fine powders.

\subsection{Particle morphology}

The CE microencapsulated particles were morphologically characterized using scanning electron microscopy (SEM) technique (Figure 3). The use of gum Arabic in the spray drying

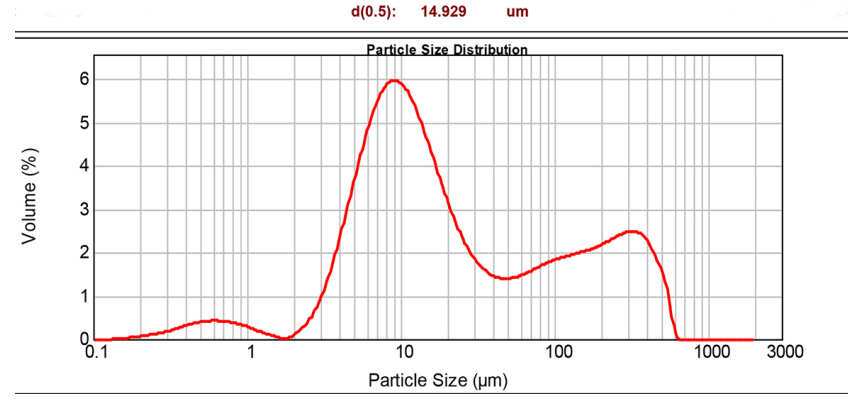

Fig. 2. Particle size distribution of spray-dried microparticles

process provided predominantly spherical particles, without visible cracks, collapses or porous structures but also clustered units which caused agglomeration of particles. This is in accordance with Botrel et al. (2014), which confirmed that microparticles produces using gums could provide degree of agglomeration. Gum Arabic used in this study, as polysaccharide contained large amount of sugars which probably had a role as filler or plasticizer preventing surface wrinkling during spray drying process. Some collapses in structure, irregular shape with some hollows probably are the result of rapid drying process of this type of carrier (Bylaitë et al., 2001; Kalušević et al., 2017; Tolun et al., 2016). (Kalušević et al., 2017) demonstrated acceptable but not ideal spherical shape of microparticles obtained using gum Arabic as encapsulant. Tolun et al. (2016) demonstrated slightly wrinkled with irregular and dented shapes with deep hollows and collapses. Gum Arabic used in this study contained large amount of low molecular weight sugars which probably had a role as filler or plasticizer preventing surface wrinkling during spray drying. Some collapses in structure, irregular shape with hollows probably are the result of rapid drying process of this type of carrier (Bylaitë et al., 2001; Kalušević et al., 2017; Tolun et al., 2016). As it is shown in Figure 3, usage of gum Arabic as a carrier gave well-formed particles with uniform sizes, without significant irregularities on the targeted microcapsules (Figure 3), which is very important for industrial application since particle shape and surface morphology could significantly affect the flow rate of obtained microparticles (Kalušević et al., 2017; Tolun et al., 2016; Tonon et al., 2009). 
Table 2. Physical properties of spray-dried chokeberry extract

\begin{tabular}{rrrr}
\hline Samples & Moisture content [\%] & Particle size $[\mu \mathrm{m}]$ & Zeta potential [mV] \\
\hline $\mathrm{CE}+\mathrm{GA}^{\mathrm{a}}$ & $4.87 \pm 0.18$ & $14.92 \pm 0.69$ & $-35.73 \pm 0.15$ \\
\hline
\end{tabular}

${ }^{a}$ CE-chokeberry extract; GA-gum Arabic.
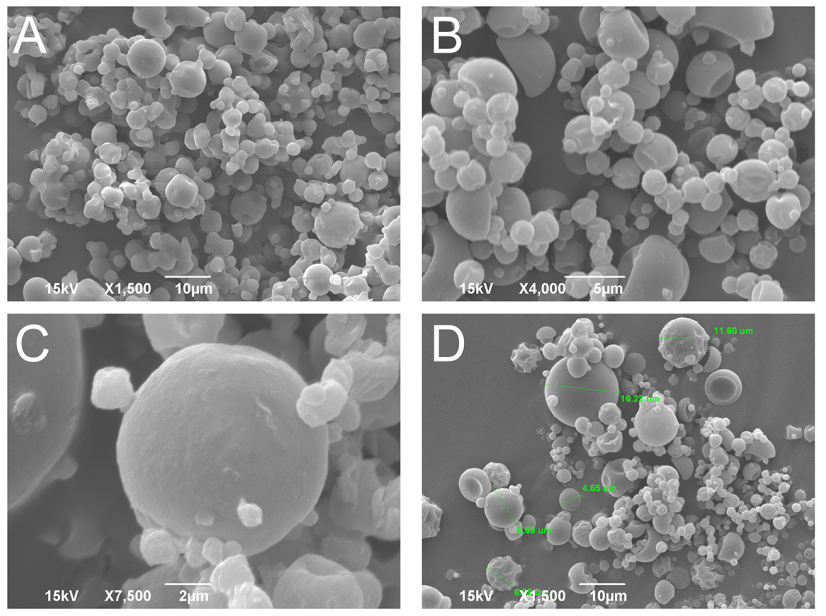

Fig. 3. SEM micrographs of spray-dried chokeberry powder in different magnifications presented on each figure

\subsection{Zeta potential}

Zeta potential was determined on spray-dried microbeads in order to examine their physical stability (Table 2). Prepared microbeads had negative values of zeta potential (-35.73 \pm $0.15 \mathrm{mV}$ ), which indicates good electrostatic stabilization. According to the previously published research, microparticles can be considered as stabile ones when the absolute value of the zeta potential is around $30 \mathrm{mV}$ due to the electric repulsion between the particles (Balanč et al., 2016). Results showed that obtained microparticles were stable, and particles repulsion was achieved, agglomeration was prevented which are exceptionally important parameters for potential powder application.

\subsection{Fourier transform infrared analysis}

This method was used to analyse the functional groups of the polymer (carrier) and chokeberry extract, as well as to examine the possible interactions between CE compounds and matrix. FTIR spectra of encapsulated CE in gum Arabic (Figure 4a) and carrier (showed several substantial picks (Figure 4). Picks in range around $1000 \mathrm{~cm}^{-1}$ correspond to the presence of -C-O in cyclic ether and alcoholic groups from polyphenols, but also of carbohydrates from carrier (Ćujić et al., 2016b; Espinosa-Andrews et al., 2010). The bands around $1600 \mathrm{~cm}^{-1}$ appeared due to the presence of this natural gum (Figure 4b) (Espinosa-Andrews et al., 2010), while the bands around $2400-2600 \mathrm{~cm}^{-1}$ resulted from the stretching vibration of $\mathrm{C}-\mathrm{H}$ bond (Espinosa-Andrews et al., 2010; de Souza et al., 2015). The spreading absorption line in a wave number region $3400-$ $3600 \mathrm{~cm}^{-1}$ has been attributed to the stretching and flexion of $\mathrm{OH}$ groups, probably from encapsulated extract polyphenols (Figure 4a) (Kalušević et al., 2017; López Córdoba et al., 2013; Stojanovic et al., 2012). FTIR analysis also showed the absence of new interactions between carrier material and microencapsulated extract. Extract was successfully incorporated into the biopolymer matrix by intermolecular interactions, during spray drying process. FTIR showed chemical stability of microparticles and used matrix is compatible material for $\mathrm{CE}$ microencapsulation.

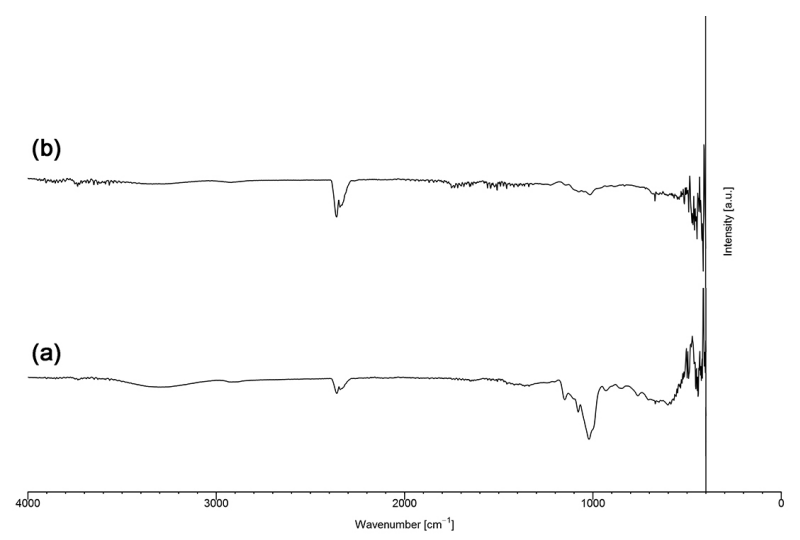

Fig. 4. FTIR spectra of (a) microencapsulated CE + gum Arabic; (b) gum Arabic

\subsection{Release studies and encapsulation efficiency of polyphenol compounds}

Phenolic compound content (total phenolics and total anthocyanin contents) as well as individual anthocyanin compounds were determined in chokeberry extract after microencapsulation process (Table 3).

Obtained microparticles had high content of encapsulated polyphenols and anthocyanins, as well as individual compounds which demonstrated that spray drying method did not cause greater degradation of active compounds due to the thermal conditions used in our study (inlet temperature of $1300 \mathrm{C}$ and outlet between 50-600C). According to the literature data, inlet temperature between 120 and $1600 \mathrm{C}$ was found as optimal for spray drying of total phenolics and anthocyanins (Bakowska-Barczak and Kolodziejczyk, 2011; Ersus and Yurdagel, 2007; Fang and Bhandari, 2011; Robert et al., 2010; Tolun et al., 2016). Thermal conditions were associated with high retention rates of these active principles, which was in accordance with Tonon et al. (2009), where powders produced using gum Arabic had the greatest polyphenols release comparing with different $\mathrm{DE}$ maltodextrins. It has been shown that higher temperature could cause lower content of polyphenols (Tolun et al., 2016). Tonon et al. (2009)) demonstrated that addition of gum Arabic increased the stability of phenolics against heating process, which was probably consequence of gum carrier properties which created good matrix structure and formed barrier between phenolics and heat. In previously mentioned study, gum Arabic as a coating material provided better protection comparing to maltodextrin. In our study, high content of released polyphenols and anthocyanins was achieved using gum Arabic as a carrier, which might be a consequence of high polyphenols affinity for this polysaccharide type carrier. Gum Arabic is highly soluble material, with good emulsifications and film creating properties which can entrap phenolic compounds during spray drying process (Kalušević et al., 2017; Tolun et al., 2016). Polyphenols can bind non-covalently to polysaccharides, which includes hydrophobic interactions and hydrogen 
Table 3. Release studies and encapsulation efficiency of microencapsulated chokeberry extract in gum Arabic

\begin{tabular}{|c|c|c|c|c|c|}
\hline & $\begin{array}{r}\text { TP } \\
{[\mathrm{mg} \mathrm{GAE} / \mathrm{g} \text { m.b.] }}\end{array}$ & $\begin{array}{r}\text { TA } \\
{[\mathrm{mg} \mathrm{CyG/g} \mathrm{m.b.]}}\end{array}$ & $\begin{array}{r}\text { Cya-gal } \\
\text { [mg/g m.b.] }\end{array}$ & $\begin{array}{r}\text { Cya-glc } \\
\text { [mg/g m.b.] }\end{array}$ & $\begin{array}{r}\text { Cya-ara } \\
\text { [mg/g m.b.] }\end{array}$ \\
\hline \multicolumn{6}{|l|}{ Before digestion process } \\
\hline Release properties & $79.20 \pm 6.46$ & $39.60 \pm 4.37$ & $21.48 \pm 4.35$ & $4.02 \pm 0.31$ & $9.41 \pm 0.86$ \\
\hline Encapsulation efficiency (\%) & $85.29 \pm 6.15$ & $83.78 \pm 9.11$ & $74.66 \pm 5.79$ & $79.61 \pm 6.52$ & $87.29 \pm 7.65$ \\
\hline \multicolumn{6}{|l|}{ After digestion process } \\
\hline Release properties & $64.15 \pm 7.46$ & $29.82 \pm 3.34$ & $17.94 \pm 8.39$ & $3.55 \pm 2.19$ & $8.33 \pm 7.72$ \\
\hline Reduction (\%) & 19.03 & 24.69 & 16.48 & 11.69 & 11.47 \\
\hline
\end{tabular}

bonds (Jakobek, 2015; Luck et al., 1994), and binding capacity is affected by polyphenol structure (molecular weight, structural flexibility and number of $\mathrm{OH}$ groups), macromolecule structure and their concentration. Besides procyanidins, anthocyanins, flavonoids and phenolic acids, chokeberries also contain lignin and non-starch polysaccharides such as cellulose, hemicellulose and pectins (Nawirska and Kwaśniewska, 2005). These polysaccharides contributed to the interaction (Le Bourvellec et al., 2005; Luck et al., 1994). Kalušević et al (2017) also showed the highest TP content using gum Arabic as encapsulant. Belščak-Cvitanović et al. (2015) and Kalušević et al. (2017) demonstrated prolonged and sustained TP release using gum as carrier. Microencapsulated CE showed similar anthocyanin profile as in previously reported chokeberry extract (Ćujić et al., 2016a). The main anthocyanin compounds were cyanidin-3-galactoside, followed by cyanidin-3arabinoside and cyanidin-3-glucoside, which was present in the lowest amounts. Microencapsulated particles exhibited high encapsulation yield (efficiency), more than $80 \%$ for total compounds, and 74.66 to $87.29 \%$ for individual anthocyanins, indicating that spray drying was a convenient technique for microencapsulation of CE (Table 3). Kalušević et al. (2017) showed the highest encapsulation efficiency (85.2\%), similar to our result using gum Arabic as a carrier. This could be explained by hydrogen bonding of hydroxyl groups from extract phenolics with polysaccharide such as gum Arabic that has a high proportion of anion fraction contributed by glucuronic arabinogalactan. Gum Arabic could actively link to extract phenolics during contact and could be able to retain phenolics extract throughout the spray drying process. Wilkowska et al. (2017) showed the carrier material effects on individual anthocyanins during spray drying process. This is in accordance with previously reported studies which demonstrated that gum Arabic was a good material for microencapsulation of phenolics and anthocyanins from acai, pomegranate and grape (Kalušević et al., 2017; Tolun et al., 2016; Tonon et al., 2009). To the best of our knowledge, there is no previously reported data of encapsulation efficiency of individual chokeberry anthocyanins, especially concerning spray drying method using gum Arabic as a carrier.

\subsection{In vitro digestion process}

One of the main objectives of this work was to determine changes in total phenolic and anthocyanins content, and dominant individual anthocyanins during gastrointestinal digestion of chokeberry extract microencapsulated particles in the presence of complex food matrix. The polyphenolics content released from microparticles after in vitro digestion process is presented in Table 3. Gastrointestinal digestion caused a decrease in the content of all polyphenolics, but percentage of reduction depends of the examined polyphenol class. The most affected by digestion process were total anthocyanins and their concentration decreased by $24.69 \%$, while individual compounds decreased by $11.47-16.48 \%$. In previous published studies (Bermudezsoto et al., 2007; Stanisavljević et al., 2015) there was also reported higher decrease of anthocyanins than total phenolics in chokeberry juice during digestion process. Literature reports about total phenolic and total anthocyanins contents of chokeberry products after digestion is little explored, especially there are no reports with microencapsulated extract in gum Arabic as a carrier. Cilla et al. (2009) showed decrease of $70 \%$ total phenolic content in fruit beverage supplemented with skimmed milk. Previous studies of encapsulated bilberry showed anthocyanins reduction of $60 \%$ during digestion process (Betz et al., 2012; Flores et al., 2014; Oidtmann et al., 2012; Wang et al., 2013), which might be a consequence of different carrier materials used in these experiments. Our results indicate that gum Arabic provides good protection of polyphenols along gastrointestinal system and stabilizes them against degradation. In vitro digestion model showed that microencapsulation is a method which can increase polyphenols and anthocyanins stability, protect them from degradation at intestinal tract conditions, and the most importantly increase their bioavailability.

\section{CONCLUSION}

Black chokeberry is one of the richest herbal sources of phenolic compounds, especially anthocyanins. Therefore, in a view of the relevancy of these substances to health, use of chokeberry extracts as a food or pharmaceuticals enriched with phenolics is very important. In this research microparticles using spray drying technique were obtained. Microparticles exhibited high encapsulation efficiency of polyphenols up to $85 \%$. Concerning microbeads characteristics, the powder produced using gum Arabic had small mean diameter, moisture content was below $5 \%$ with well-formed spherical shapes, which is very important for the industrial perspective. Gum Arabic as a carrier provided suitable polyphenolics release from microparticles. Gum Arabic served as good protection agents for phenolics subjected to in vitro digestion method. Our results showed that chokeberry microparticles obtained by spray drying method could be useful supplements or functional food.

\section{ACKNOWLEDGMENTS}

Acknowledgment. The authors acknowledge their gratitude to the Ministry of Education, Science and Technological Development of the Republic of Serbia for financial support, Project No. 46013 and Project No. 173005. 


\section{REFERENCES}

Bakowska-Barczak, A. M. and Kolodziejczyk, P. P. (2011). Black currant polyphenols: Their storage stability and microencapsulation, Industrial Crops and Products 34(2): 1301-1309.

Balanč, B., Trifković, K., Đorđević, V., Marković, S., Pjanović, R., Nedović, V. and Bugarski, B. (2016). Novel resveratrol delivery systems based on alginate-sucrose and alginatechitosan microbeads containing liposomes, Food Hydrocolloids 61: 832-842.

Belščak-Cvitanović, A., Lević, S., Kalušević, A., Špoljarić, I., Đorđević, V., Komes, D., Mršić, G. and Nedović, V. (2015). Efficiency Assessment of Natural Biopolymers as Encapsulants of Green Tea (Camellia sinensis L.) Bioactive Compounds by Spray Drying, Food and Bioprocess Technology 8(12): 2444-2460.

Belščak-Cvitanović, A., Stojanović, R., Manojlović, V., Komes, D., Cindrić, I. J., Nedović, V. and Bugarski, B. (2011). Encapsulation of polyphenolic antioxidants from medicinal plant extracts in alginate-chitosan system enhanced with ascorbic acid by electrostatic extrusion, Food Research International 44(4): 1094-1101.

Bermudezsoto, M., Tomasbarberan, F. and Garciaconesa, M. (2007). Stability of polyphenols in chokeberry (Aronia melanocarpa) subjected to in vitro gastric and pancreatic digestion, Food Chemistry 102(3): 865-874.

Betz, M., Steiner, B., Schantz, M., Oidtmann, J., Mäder, K., Richling, E. and Kulozik, U. (2012). Antioxidant capacity of bilberry extract microencapsulated in whey protein hydrogels, Food Research International 47(1): 51-57.

Botrel, D. A., de Barros Fernandes, R. V., Borges, S. V. and Yoshida, M. I. (2014). Influence of wall matrix systems on the properties of spray-dried microparticles containing fish oil, Food Research International 62: 344-352.

Bräunlich, M., Slimestad, R., Wangensteen, H., Brede, C., Malterud, K. and Barsett, H. (2013). Extracts, Anthocyanins and Procyanidins from Aronia melanocarpa as Radical Scavengers and Enzyme Inhibitors, Nutrients 5(3): 663-678.

Bylaitë, E., Rimantas Venskutonis, P. and Mapdpierienë, R. (2001). Properties of caraway ( Carum carvi L.) essential oil encapsulated into milk protein-based matrices, European Food Research and Technology 212(6): 661-670.

Castañeda-Ovando, A., Pacheco-Hernández, M. d. L., PáezHernández, M. E., Rodríguez, J. A. and Galán-Vidal, C. A. (2009). Chemical studies of anthocyanins: A review, Food Chemistry 113(4): 859-871.

Cilla, A., González-Sarrías, A., Tomás-Barberán, F. A., Espín, J. C. and Barberá, R. (2009). Availability of polyphenols in fruit beverages subjected to in vitro gastrointestinal digestion and their effects on proliferation, cell-cycle and apoptosis in human colon cancer Caco-2 cells, Food Chemistry 114(3): 813-820.

Ćujić, N., Šavikin, K., Janković, T., Pljevljakušić, D., Zdunić, G. and Ibrić, S. (2016a). Optimization of polyphenols extraction from dried chokeberry using maceration as traditional technique, Food Chemistry 194: 135-142.

Ćujić, N., Trifković, K., Bugarski, B., Ibrić, S., Pljevljakušić, D. and Šavikin, K. (2016b). Chokeberry (Aronia melanocarpa L.) extract loaded in alginate and alginate/inulin system, Industrial Crops and Products 86: 120-131. de Souza, V. B., Thomazini, M., Balieiro, J. C. d. C. and FávaroTrindade, C. S. (2015). Effect of spray drying on the physicochemical properties and color stability of the powdered pigment obtained from vinification byproducts of the Bordo grape (Vitis labrusca), Food and Bioproducts Processing 93: 3950.

Dib Taxi, C. M. A., De Menezes, H. C., Santos, A. B. and Grosso, C. R. F. (2003). Study of the microencapsulation of camucamu ( Myrciaria dubia ) juice, Journal of Microencapsulation 20(4): 443-448.

Ersus, S. and Yurdagel, U. (2007). Microencapsulation of anthocyanin pigments of black carrot (Daucus carota L.) by spray drier, Journal of Food Engineering 80(3): 805-812.

Espinosa-Andrews, H., Sandoval-Castilla, O., Vázquez-Torres, H., Vernon-Carter, E. J. and Lobato-Calleros, C. (2010). Determination of the gum Arabic-chitosan interactions by Fourier Transform Infrared Spectroscopy and characterization of the microstructure and rheological features of their coacervates, Carbohydrate Polymers 79(3): 541-546.

Fang, Z. and Bhandari, B. (2011). Effect of spray drying and storage on the stability of bayberry polyphenols, Food Chemistry 129(3): 1139-1147.

Flores, F. P., Singh, R. K., Kerr, W. L., Pegg, R. B. and Kong, F. (2014). Total phenolics content and antioxidant capacities of microencapsulated blueberry anthocyanins during in vitro digestion, Food Chemistry 153: 272-278.

González-Molina, E., Moreno, D. A. and García-Viguera, C. (2008). Aronia-Enriched Lemon Juice: A New Highly Antioxidant Beverage, Journal of Agricultural and Food Chemistry 56(23): 11327-11333.

Goyal, A., Sharma, V., Sihag, M. K., Tomar, S., Arora, S., Sabikhi, L. and Singh, A. (2015). Development and physicochemical characterization of microencapsulated flaxseed oil powder: A functional ingredient for omega-3 fortification, Powder Technology 286: 527-537.

Horszwald, A., Julien, H. and Andlauer, W. (2013). Characterisation of Aronia powders obtained by different drying processes, Food Chemistry 141(3): 2858-2863.

Idham, Z., Muhamad, I. I. and Sarmidi, M. R. (2012). Degradation kinetics and color stability of spray-dried encapsulated anthocyanins from Hibiscus sabdariffa L.: stability of spray dried anthocyanins, Journal of Food Process Engineering 35(4): 522-542.

Jakobek, L. (2015). Interactions of polyphenols with carbohydrates, lipids and proteins, Food Chemistry 175: 556-567.

Kalušević, A. M., Lević, S. M., Čalija, B. R., Milić, J. R., Pavlović, V. B., Bugarski, B. M. and Nedović, V. A. (2017). Effects of different carrier materials on physicochemical properties of microencapsulated grape skin extract, Journal of Food Science and Technology 54(11): 3411-3420.

Kokotkiewicz, A., Jaremicz, Z. and Luczkiewicz, M. (2010). Aronia Plants: A Review of Traditional Use, Biological Activities, and Perspectives for Modern Medicine, Journal of Medicinal Food 13(2): 255-269.

Kulling, S. and Rawel, H. (2008). Chokeberry (Aronia melanocarpa) - A Review on the Characteristic Components and Potential Health Effects, Planta Medica 74(13): 16251634. 
Le Bourvellec, C., Bouchet, B. and Renard, C. (2005). Noncovalent interaction between procyanidins and apple cell wall material. Part III: Study on model polysaccharides, Biochimica et Biophysica Acta (BBA) - General Subjects 1725(1): 10-18

López Córdoba, A., Deladino, L. and Martino, M. (2013). Effect of starch filler on calcium-alginate hydrogels loaded with yerba mate antioxidants, Carbohydrate Polymers 95(1): 315323.

Luck, G., Liao, H., Murray, N. J., Grimmer, H. R., Warminski, E. E., Williamson, M. P., Lilley, T. H. and Haslam, E. (1994). Polyphenols, astringency and proline-rich proteins, Phytochemistry 37(2): 357-371.

Minekus, M., Alminger, M., Alvito, P., Ballance, S., Bohn, T. Bourlieu, C., Carrière, F., Boutrou, R., Corredig, M., Dupont, D., Dufour, C., Egger, L., Golding, M., Karakaya, S., Kirkhus, B., Le Feunteun, S., Lesmes, U., Macierzanka, A., Mackie, A., Marze, S., McClements, D. J., Ménard, O., Recio, I., Santos, C. N., Singh, R. P., Vegarud, G. E., Wickham, M. S. J., Weitschies, W. and Brodkorb, A. (2014). A standardised static in vitro digestion method suitable for food - an international consensus, Food Funct. 5(6): 1113-1124.

Nawirska, A. and Kwaśniewska, M. (2005). Dietary fibre fractions from fruit and vegetable processing waste, Food Chemistry 91(2): 221-225.

Oidtmann, J., Schantz, M., Mäder, K., Baum, M., Berg, S., Betz, M., Kulozik, U., Leick, S., Rehage, H., Schwarz, K. and Richling, E. (2012). Preparation and Comparative Release Characteristics of Three Anthocyanin Encapsulation Systems, Journal of Agricultural and Food Chemistry 60(3): 844-851.

Ph.Eur.8.0. (2014). European Pharmacopoeia 8.0., Strasbourg Cedex, France: Council of Europe.

Ph.Yug.V (2000). 5th edn, Yugoslavian Pharmacopeia (Pharmacopoea Jugoslavica), National Institute for Health Protection, Contemporaneous administration, Belgrade, Serbia.

Righetto, A. M. and Netto, F. M. (2005). Effect of Encapsulating Materials on Water Sorption, Glass Transition and Stability of Juice From Immature Acerola, International Journal of Food Properties 8(2): 337-346.

Robert, P., Gorena, T., Romero, N., Sepulveda, E., Chavez, J. and Saenz, C. (2010). Encapsulation of polyphenols and anthocyanins from pomegranate (Punica granatum) by spray drying: Encapsulation of polyphenols and anthocyanins, International Journal of Food Science \& Technology 45(7): 13861394.

Rugina, D., Sconta, Z., Leopold, L., Pintea, A., Bunea, A. and Socaciu, C. (2012). Antioxidant Activities of Chokeberry Extracts and the Cytotoxic Action of Their Anthocyanin Fraction on HeLa Human Cervical Tumor Cells, Journal of Medicinal Food 15(8): 700-706.

Sainova, I., Pavlova, N. V., Alexieva, B., Vavrek, I., Nikolova, E., Kuzmanova, S., Markova, T., Krachanova, M., Denev, P. and Vavrek, D. (2012). Chemoprotective, antioxidant and immunomodulatory in vitro effects of Aronia melanocarpa total extract on laboratory-cultivated normal and malignant cells.

Stanisavljević, N., Samardžić, J., Janković, T., Šavikin, K., Mojsin, M., Topalović, V. and Stevanović, M. (2015). Antioxidant and antiproliferative activity of chokeberry juice phenolics during in vitro simulated digestion in the presence of food matrix, Food Chemistry 175: 516-522.
Stojanovic, R., Belscak-Cvitanovic, A., Manojlovic, V., Komes, D., Nedovic, V. and Bugarski, B. (2012). Encapsulation of thyme (Thymus serpyllum L.) aqueous extract in calcium alginate beads, Journal of the Science of Food and Agriculture 92(3): 685-696.

Sueiro, L., Yousef, G., Seigler, D., de Mejia, E., Grace, M. and Lila, M. (2006). Chemopreventive Potential of Flavonoid Extracts from Plantation-Bred and Wild Aronia melanocarpa (Black Chokeberry) Fruits, Journal of Food Science 71(8): C480C488.

Tolun, A., Altintas, Z. and Artik, N. (2016). Microencapsulation of grape polyphenols using maltodextrin and gum arabic as two alternative coating materials: Development and characterization, Journal of Biotechnology 239: 23-33.

Tonon, R. V., Brabet, C., Pallet, D., Brat, P. and Hubinger, M. D. (2009). Physicochemical and morphological characterisation of açai ( Euterpe oleraceae Mart.) powder produced with different carrier agents, International Journal of Food Science $\mathcal{E}$ Technology 44(10): 1950-1958.

Versantvoort, C., Van de Kamp, E. and Rompelberg, C. (2004). Development of an in vitro digestion model to determine the bioaccessibility of contaminants from food, Report No.320102002, National Institute for Public Health and the Environment, Bilthoven, Netherlands.

Wang, Z., Li, Y., Chen, L., Xin, X. and Yuan, Q. (2013). A Study of Controlled Uptake and Release of Anthocyanins by Oxidized Starch Microgels, Journal of Agricultural and Food Chemistry 61(24): 5880-5887.

Waterman, P. G. and Mole, S. (1994). Analysis of Phenolic Plant Metabolites, Wiley. Google-Books-ID: oJNsQgAACAAJ.

Wilkowska, A., Ambroziak, W., Adamiec, J. and Czyżowska, A. (2017). Preservation of Antioxidant Activity and Polyphenols in Chokeberry Juice and Wine with the Use of Microencapsulation: Preservation of juice and wine polyphenols, Journal of Food Processing and Preservation 41(3): e12924. 